\title{
Nerve Growth Factor Stimulation of GAP-43 Phosphorylation in Intact Isolated Growth Cones
}

\author{
Karina F. Meiri and Debra Burdick \\ Department of Pharmacology, SUNY Health Science Center, Syracuse, New York 13210
}

\begin{abstract}
Phosphorylation of the nervous system-specific growth cone protein GAP-43 by kinase $C$ in vivo occurs exclusively in growth cones and distal axons, and the onset of this phosphorylation is delayed relative to the onset of axonogenesis, with the delay predicated on the time needed for axons to reach the vicinity of their targets (Meiri et al., 1991). We have used a subcellular fraction of intact growth cones (IGCs) to investigate whether this induction of GAP-43 phosphorylation can be influenced by target-derived substances, and show here that increased phosphorylation of GAP-43 can be both stimulated and maintained by NGF at concentrations of $2 \times 10^{-10} \mathrm{~m}$. This low concentration of NGF and the subsequent phosphorylation of GAP-43 are both consistent with the interpretation that phosphorylation is due to the binding of NGF to a biologically active high-affinity receptor. Second, we used the monoclonal antibody $2 \mathrm{G} 12$ to show that the NGF-stimulated phosphorylation of GAP-43 occurs on serine $^{41}$, the kinase $C$ phosphorylation site, consistent with the results seen in vivo. Levels of phosphorylated GAP-43 in the intact IGCs are also modulated by calcium-stimulated dephosphorylation that could be inhibited by EGTA but not okadaic acid and that therefore resembled the calcineurinstimulated dephosphorylation reported in vitro. The results suggest that the spatial and temporal regulation of GAP-43 phosphorylation that occurs during axonogenesis in vivocan be regulated by target-derived neurotropic molecules, specifically NGF.
\end{abstract}

The establishment of appropriate synaptic connections is crucial for the development of the nervous system, but the molecular basis for those functions of motility, adhesion to the substrate, and pathfinding that are responsible for target-directed axon outgrowth is poorly understood (reviewed by Bray and Hollenbeck, 1988). For example, the growth cone that is transiently generated at the tips of developing or regenerating axons interacts with various soluble or substrate-associated neurotropic

\footnotetext{
Received Mar. 11, 1991; revised May 6, 1991; accepted May 23, 1991.

This study could not have been accomplished without the generous gift of $2.5 \mathrm{~S}$ NGF from Dr. E. M. Johnson, whom we also thank for helpful discussions. We thank Dr. R. Paxton of the Beckman Research Institute at City of Hope, Duarte, $\mathrm{CA}$, for sequencing, and Jared Lucas for assistance. We appreciate the experimental contributions made by Dr. Joanne Taylor at the start of the study and acknowledge Dr. J. Schwob for careful reading of the manuscript. This work was supported by NIH Grant NS26091 and a Basil O'Connor Starter Scholar Award from the March of Dimes.

Correspondence should be addressed to Dr. Karina F. Meiri, Department of Pharmacology, SUNY Health Science Center, 750 East Adams Street, Syracuse, NY 13210

Copyright (c) 1991 Society for Neuroscience $0270-6474 / 91 / 113155-12 \$ 05.00 / 0$
}

factors, but it is not known how these extracellular signals are transduced to generate an intracellular response (reviewed by Lander, 1987). Because the growth cone responds to neurotropic factors by rather stereotyped, albeit dramatic, alterations in morphology, manifested as extension and retraction of filopodia and lamellae that then orient the growing axon along appropriate pathways (see, e.g., Tosney and Landmesser, 1985a,b; Caudy and Bentley, 1986; Gundersen, 1987; Chitnis and Kuwada, 1990; Kuwada et al., 1990), one approach to understanding the molecular basis for the directionality of axon outgrowth is to determine how growth cone morphology is controlled by extracellular stimuli. By analogy with other motile cells, it is likely that the alterations to growth cone shape that occur following dynamic interactions with the substrate (Tomaselli et al., 1986; Pfenninger, 1987; Matsunaga et al., 1988) are mediated via the proteins of the membrane skeleton; this structure, located subjacent to the plasma membrane, links the membrane with the actin filamentous cytoskeleton and is responsible for maintaining cell shape (reviewed by Mangeat, 1988).

The so-called "growth-associated" protein GAP-43 is a nervous system-specific phosphoprotein that is specifically enriched in the membrane skeleton of growth cones (Meiri et al., 1986, 1988; Meiri and Gordon-Weeks, 1990). Interest in this protein arose following observations that its axonal transport is dramatically induced in neurons that are growing axons during development or regeneration but that this induction is not reinstated in the injured axons of neurons that do not normally regenerate, such as the mammalian CNS, suggesting that it may be intimately involved in axon outgrowth (Skene and Willard, 1981). While the enrichment of GAP-43 in the membrane skeleton, together with its localization at areas that are tightly attached to the substrate, also supports the notion that GAP-43 is involved in membrane cytoskeleton interactions in the growth cone (Meiri et al., 1986; Meiri and Gordon-Weeks, 1990), it is not known what these interactions may be or how they may be regulated. It seems likcly that posttranslational modifications of GAP-43 will be important in modifying its behavior; in fact, we have recently shown that phosphorylation of GAP-43 by kinase $\mathrm{C}$ in vivo occurs exclusively in growth cones and distal axons. Furthermore, the onset of this phosphorylation is delayed relative to the onset of axonogenesis, with the delay predicated on the time needed for axons to reach the vicinity of their targets (Meiri et al., 1991). These data, together with demonstrations that GAP-43 phosphorylation by kinase $\mathrm{C}$ can arise as a consequence of stimulation of exocytosis (Dekker et al., 1989), membrane depolarization (Dekker et al., 1990), and treatment with muscarinic agonists (Van Hoof et al., 1989), suggest a role for GAP-43 in the response of the growth cone membrane skeleton to the transduction of extracellular signals. 
Because GAP-43 phosphorylation by kinase $\mathrm{C}$ in vivo is so precisely regulated in a manner that suggests an involvement of the proximity of growing axons to their targets, we have considered the possibility that it may be affected by target-derived neurotropic factors. In order to approach this question, we had to circumvent the two major drawbacks of using either primary neuronal cultures or cell lines to study phosphorylation events in growth cones, namely, the difficulties of differentiating between the biochemical reactions that occur in the growth cone and those that are ongoing elsewhere in the neuron, as well as the problems involved in correlating the events that are occurring in the regenerating neurites actually present in primary tissue culture, with those that occur during axonogenesis in vivo. We avoided these problems by using a subcellular fractionation procedure to isolate intact growth cones from the forebrains of fetal or neonatal rats (Gordon-Weeks and Lockerbie, 1984; Gordon-Weeks, 1987). Not only are the ultrastructures of the isolated growth cones (IGCs) prepared by this method well preserved (Gordon-Weeks and Lockerbie, 1984), but their ability to attach to a substrate in a manner that is dependent on actin polymerization (Gordon-Weeks and Lockerbie, 1984), as well as to take up neurotransmitters and release them upon depolarization (Lockerbie et al., 1985), furthermore suggests that aspects of their physiological integrity are also maintained. We show here the use of this model system to study signal transduction processes in growth cones: the intact IGCs are able to synthesize radiolabeled A TP from ${ }^{32} \mathrm{P}$-orthophosphate, enabling us to detect increased phosphate incorporation into specific growth cone proteins after their phosphorylation had been stimulated by specific kinases. Phosphorylation of GAP-43 in intact IGCs was stimulated by $2.5 \mathrm{~S} N G F$ with a $K_{d}$ of $2 \times 10^{-10} \mathrm{M}$, consistent with the interpretation that phosphorylation occurred subsequent to the binding of NGF to a high-affinity receptor. This phosphorylation occurred on serine ${ }^{41}$, the residue phosphorylated by kinase $C$, enabling us to use our antibody that specifically recognizes phosphoserine ${ }^{41}$ on GAP-43, to show that steady state levels of phosphorylated GAP-43 in growth cones are increased and maintained during incubation with NGF. We have also demonstrated that ongoing dephosphorylation of GAP. 43 in intact IGCs in a manner that is stimulated by the presence of extracellular calcium. The dephosphorylation of GAP-43 can be prevented by incubating IGCs with EGTA but is unaffected by okadaic acid. This result is consistent with the finding that dephosphorylation of GAP-43 by calcineurin occurs in vitro (Liu and Storm, 1989). The results are discussed with reference to both the neurotrophic and neurotropic actions of NGF as well as the regulation of interactions between proteins of the growth cone membrane skeleton by extracellular signals.

\section{Materials and Methods}

\section{Preparation of isolated growth cones}

Septal and hippocampal areas were dissected from postnatal day 1-4 (P1-4; day of birth is $\mathrm{P} 1$ ) rat forebrains and used in the preparation of isolated growth cones (IGCs) as has been described previously (Meiri and Gordon-Weeks, 1990) with the following modifications: material banding at the interface between the sample and the $7 \%$ Ficoll solution following the first density gradient step was diluted 1:5 by adding Krebs's solution dropwise while stirring over ice (except where otherwise stated, Krebs's solution contains $145 \mathrm{~mm} \mathrm{NaCl}, 5 \mathrm{~mm} \mathrm{KCl}, 1.3 \mathrm{~mm} \mathrm{MgCl}$, $1.2 \mathrm{mM} \mathrm{NaH}_{2} \mathrm{PO}_{4}, 10 \mathrm{~mm}$ glucose, $20 \mathrm{~mm}$ HEPES, pH 7.4). The resultant suspension was centrifuged at $14,500 \times g_{\mathrm{av}}$ for $50 \mathrm{~min}$ at $4^{\circ} \mathrm{C}$, and the pellet was resuspended in Krebs's solution at a concentration of about $3 \mathrm{mg} / \mathrm{ml}$.

\section{Phosphorylations}

In vitro. Freshly prepared IGCs in Krebs's buffer at a concentration of about $3 \mathrm{mg} / \mathrm{ml}$ were pelleted in a microfuge at $4^{\circ} \mathrm{C}$ and then osmotically lysed in a solution containing (final concentrations) $25 \mathrm{~mm}$ Tris (pH 7.4), $10 \mathrm{~mm} \mathrm{MgCl}_{2}, 1 \mathrm{~mm}$ EGTA, and $1 \mathrm{~mm}$ dithiothreitol, by brief sonication. The suspension was centrifuged at $100,000 \times g$ for $30 \mathrm{~min}$ at $4^{\circ} \mathrm{C}$, and the pellets were resuspended in the same solution at a final concentration of $1.5 \mathrm{mg} / \mathrm{ml}$. After preincubation of $75 \mu \mathrm{g}$ aliquots for $90 \mathrm{sec}$ at room temperature, phosphorylation was initiated by the addition of $200 \mu \mathrm{M} \gamma^{-32} \mathrm{P}-\mathrm{ATP}$ (specific activity, $5 \mathrm{Ci} / \mathrm{mmol}$ ). In some cases, phosphorylation was stimulated with NGF; precise details of reaction conditions appear in the appropriate Results section. Phosphorylation was stopped after $25 \mathrm{sec}$ by the addition of boiling 1\% SDS solution.

Intact IGCs. Intact septal and hippocampal IGCs at a concentration of about $3 \mathrm{mg} / \mathrm{ml}$ were preincubated for $15 \mathrm{~min}$ at $37^{\circ} \mathrm{C}$ in Krebs's solution, and then ${ }^{32} \mathrm{P}$-orthophosphate was added to a final concentration of $1 \mathrm{mCi}{ }^{32} \mathrm{P} / \mathrm{mg}$ IGCs. After incubation for $30 \mathrm{~min}$ at $37^{\circ} \mathrm{C}$ with shaking, the suspensions were microfuged briefly to remove unincorporated phosphate. The pellets were then resuspended in Krebs's buffer at a concentration of $3 \mathrm{mg} / \mathrm{ml}$, and aliquots containing $75 \mu \mathrm{g}$ of protein were diluted 1:1 with Krebs's buffer that contained specific stimulators of phosphorylation (see Results). In some cases where dephosphorylation was to be studied, the Krebs's solution also contained $1.2 \mathrm{mM} \mathrm{CaCl}_{2}$ plus $1 \mu \mathrm{M} \mathrm{A23187,} \mathrm{or} 1 \mathrm{~mm}$ EGTA, or $1 \mu \mathrm{M}$ okadaic acid. For maximal and reproducible stimulation of phosphorylation, it was crucial to acratc the samples every minute for $10 \mathrm{sec}$ by gently bubbling through air containing $5 \% \mathrm{CO}_{2}$. This was particularly important for long-term $(>20$ min) experiments. Stimulation of phosphorylation after specific times (see Results) was terminated by dropping the samples into liquid nitrogen.

\section{Identification of serine ${ }^{41}$ as the NGF-stimulated phosphorylation site}

Phosphorylation of GAP-43 was stimulated in intact IGCs with NGF, as described above, and GAP-43 was then purified from the IGCs by extraction with base followed by reverse-phase HPLC. Purified GAP43 was digested to completion with trypsin, and the resultant peptides were separated by reverse-phase HPLC using a $\mathrm{C}_{4}$ column, as previously described (Meiri et al., 1991). Phosphate incorporation into the tryptic peptides was detected by Cerenkov counting, and the peptides were then dot blottcd onto Immobilon paper. Immunorcactivity of the peptides adsorbed onto the dot blot was detected with the monoclonal antibody 2 G12 that reacts specifically with phosphoserine ${ }^{41}$ (Meiri et al., 1991) and visualized using biotinylated secondary antibodies and a biotinavidin horseradish peroxidase system (Vectastain, Vector Labs., Burlingame, CA). Results were compared with control (unstimulated) IGCs and IGCs that had their phosphorylation stimulated in vitro with NGF.

\section{General techniques}

Electrophoresis and Western blotting. One-dimensional analysis of proteins (Laemmli, 1970) used either $10 \%$ or $3-14 \%$ gradient SDS gels. Two-dimensional isoelectric focusing (IEF) gels were run for 7000 $\mathrm{V} / \mathrm{hr}$ in the first dimension to focus acidic proteins completely including GAP-43, and on 10\% SDS-PAGE in the second dimension (Meiri et al., 1986, 1988, 1991; Meiri and Gordon-Weeks, 1990). Gels were stained with Coomassie blue, and scanning absorbance densitometry at $415 \mathrm{~nm}$ was performed on wet gels using a Shimadzu CS-9000 densitometer. Western blotting was carried out as described previously (Meiri and Gordon-Weeks, 1990). Proteins were transferred onto Immobilon paper, and immunorcactivity was visualized on Western blots as described above. To perform scanning reflectance densitometry (at 500 $\mathrm{nm}$ ) of Western blots, the amount of GAP-43 loaded onto the gels was adjusted so that the signal obtained from the Western blot was not saturated and was within the linear range of the densitometer, by comparison with standard curves that were run in parallel. Protein concentrations were determined using a Coomassie-based assay (Bradford, 1976) with modifications (Read and Northcote, 1981; Gogstadt and Krutnes, 1982) to enable measurement of membrane proteins. Bovine serum albumin was used as standard.

Autoradiography and scintillation counting. For autoradiography, gels were dried and exposed to Kodak X-Omat-K or X-Omat-AR film. For scintillation counting, pieces cut from dried gels were solubilized in hydrogen peroxide, and liquid scintillant was added prior to counting. 

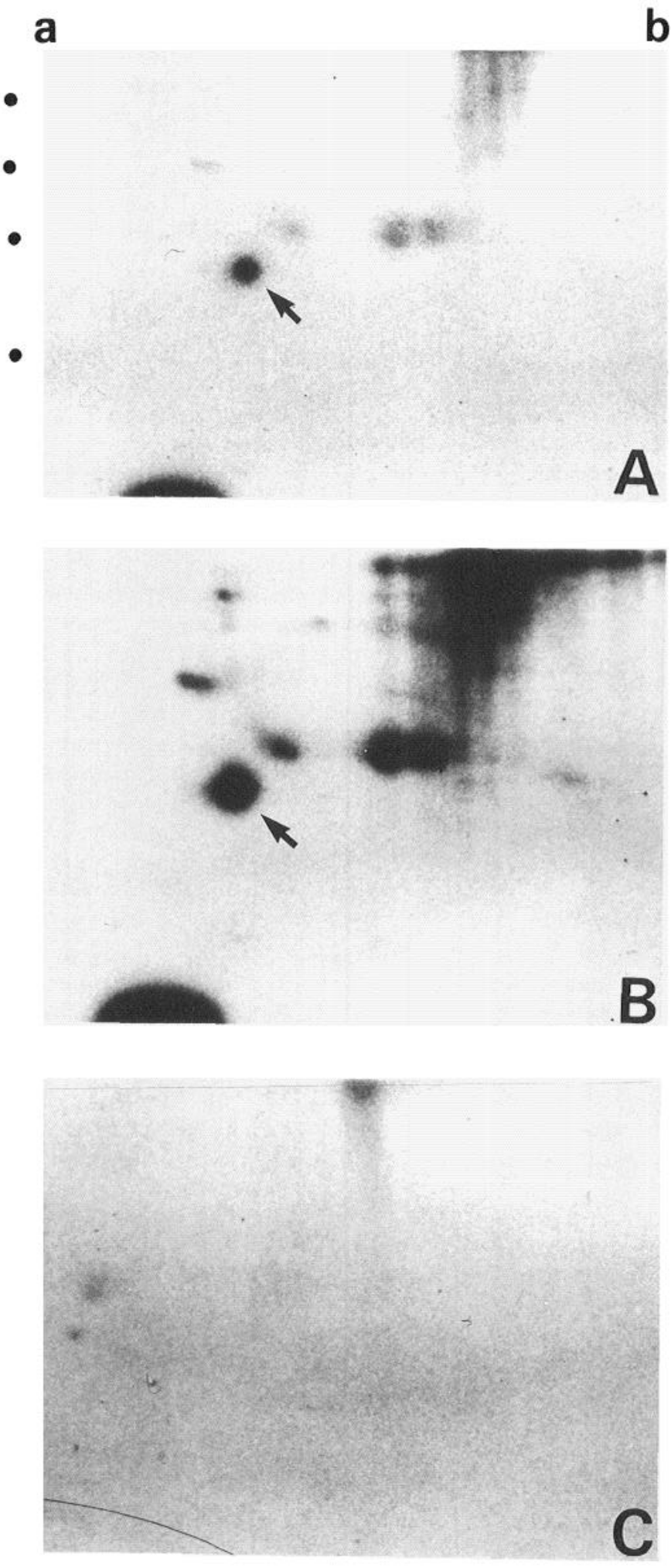

Figure 1. Phosphorylation of proteins in intact isolated growth cones. $A$, Autoradiograph of a $30 \mu \mathrm{g}$ aliquot of IGC proteins that had been preincubated with ${ }^{32} \mathrm{P}$-orthophosphate as described in Materials and Methods. Proteins were separated in the first (horizontal) dimension by IEF PAGE: left side $(a)$, pI 4.2; right side $(b)$, pI 8.1. The second dimension was a $10 \%$ SDS gel. Migration of GAP-43 is marked with an arrow. Molecular weight markers from top to bottom are 180, 97, 58, and $36 \mathrm{kDa}$. The autoradiograph was exposed for $12 \mathrm{hr}$. B, Autoradiograph of a $30 \mu \mathrm{g}$ aliquot derived from the same sample as above that had been incubated for $5 \mathrm{~min}$ with $10 \mathrm{~nm}$ PDBU. 2-D Electrophoresis

\section{Results}

Phosphorylation of proteins in intact IGCs: treatment with phorbol ester

In order to investigate whether intact IGCs are able to synthesize ATP and then use it to phosphorylate IGC proteins, we prepared IGCs from P1 rat forebrains and incubated them with ${ }^{32} \mathrm{P}$-orthophosphate. Examination of autoradiographs of proteins that had been separated by SDS-PAGE showed that radiolabeled ATP, synthesized by the IGCs, had indeed been incorporated into protein. Maximal and reproducible incorporation occurred when (1) the Krebs's solution containing the ${ }^{32} \mathrm{P}$-orthophosphate in which the IGCs were incubated did not contain either phosphate or calcium ions, (2) incubation of the IGC protein was for $30 \mathrm{~min}$ and used $1 \mathrm{mCi}^{32} \mathrm{P}$-orthophosphate/mg IGC protein, and (3) the suspensions were aerated with air that contained $5 \%$ $\mathrm{CO}_{2}$ for $10 \mathrm{sec}$ every minute (Fig. $1 \mathrm{~A}$ ). We next incubated the intact, prelabeled IGCs for $5 \mathrm{~min}$ in the presence of $10 \mathrm{~nm}$ phorbol dibutyrate (PDBU), in order to activate protein kinase C. Phosphorylation of specific kinase C substrates were identified by comparing autoradiographs of radiolabeled proteins with controls (Fig. 1B). GAP-43 was identified as one of the kinase $C$ substrates in two ways: by comparison of the autoradiographs with previously published autoradiographs of 2-D gels that had been prepared and run in precisely the same way (Meiri et al., 1986, 1988) and also by its immunoreactivity on 2-D Western blots with the monoclonal antibody $5 \mathrm{E} 7$ as has been described previously (Meiri et al., 1991; results not shown).

The stimulation of GAP- 43 phosphorylation by PDBU was determined by scintillation counting of the ${ }^{32} \mathrm{P}$-radiolabeled GAP43 spots that were excised from the 2-D gels (Fig. $1 B$; see also Fig. 2C). The maximal stimulation of phosphorylation was fourto fivefold, similar to the levels that were detected in a series of experiments that used intact synaptosomes to study similar phosphorylation reactions (Yip and Kelly, 1989). In control experiments, any phosphorylation occurring subsequent to the rapid freezing of the IGCs in liquid nitrogen was ruled out by adding $\gamma-{ }^{32}$ P-ATP to the IGCs as they were frozen and then processing them for 2-D gels as described. These samples showed barely detectable phosphate incorporation into IGC proteins only after extended exposure of the x-ray film (Fig. 1C).

\section{$N G F$-stimulated phosphorylation of GAP-43 in intact growth cones}

In vivo, kinase $\mathrm{C}$ phosphorylation of GAP-43 in distal axons and growth cones occurs after the onset of axonogenesis, at a time when growing axons are in the proximity of their targets, thereby suggesting that the onset of GAP- 43 phosphorylation could be influenced by target-derived molecules (Meiri et al., 1991). One likely candidate would be the neurotrophic and chemotropic factor NGF, which has been shown to cause the activation of a number of intracellular kinases in cells bearing a high-affinity NGF receptor (McTigue et al., 1985; Cremins et

\footnotetext{
was carried out as above. The migration of GAP- 43 is shown with an arrow. Note the increased phosphorylation of GAP-43 and other IGC proteins. Autoradiograph was also exposed for $12 \mathrm{hr}$. C, Autoradiograph of $30 \mu \mathrm{g}$ aliquot of IGC proteins from same sample, which had $200 \mu \mathrm{M}$ $\gamma{ }^{-32} \mathrm{P}-\mathrm{ATP}$ added to them as they were being frozen in liquid nitrogen. Autoradiograph was exposed for $4 \mathrm{~d}$. Note that there are no radiolabeled proteins. These are representative autoradiographs; the experiments were repeated seven times.
} 

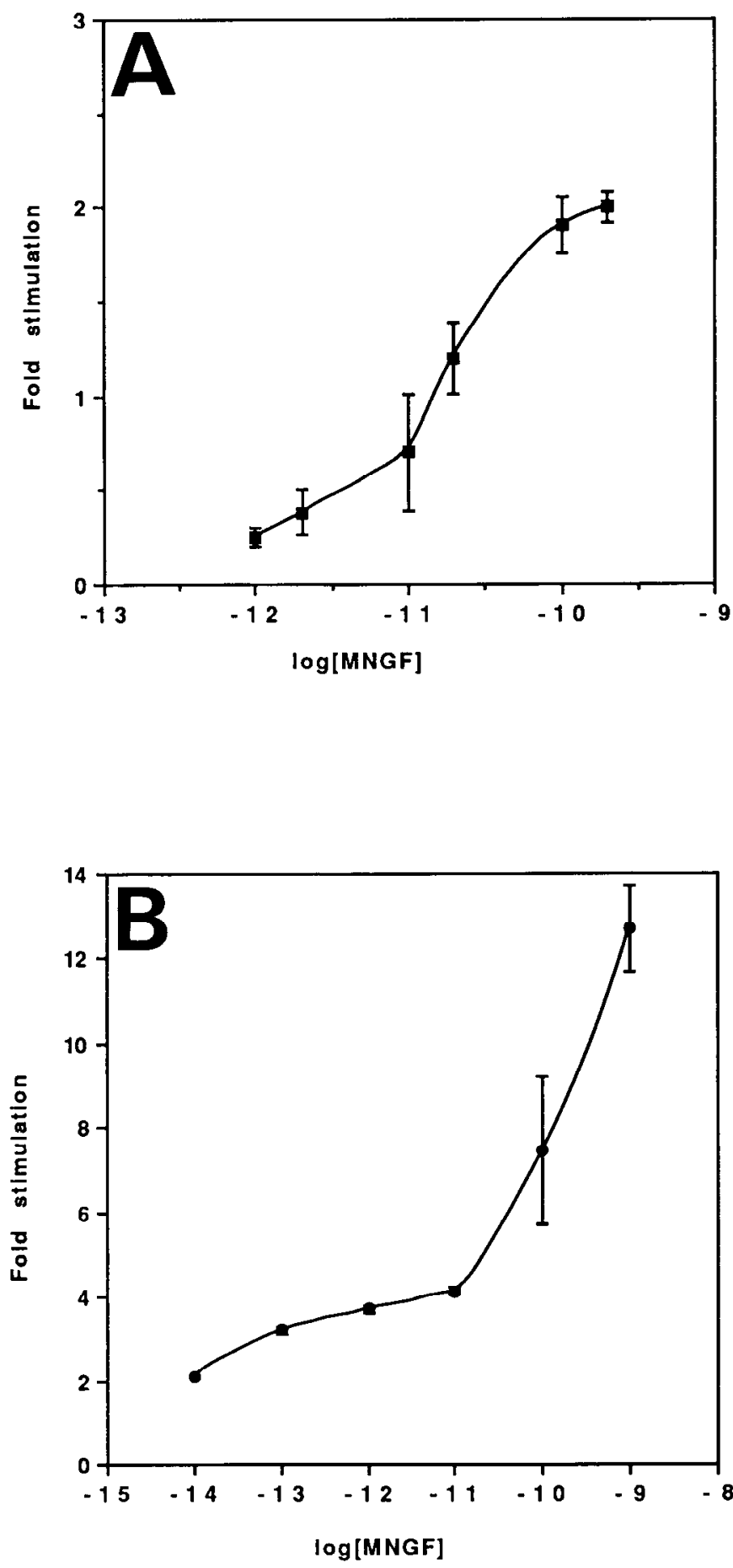

Figure 2. Stimulation of GAP-43 phosphorylation by NGF. $A$, Doseresponse curve generated from the scintillation counts derived from GAP-43 spots cut out of 2-D gels following separation of IGC protein that had been incubated with NGF and ${ }^{32} \mathrm{P}$-orthophosphate. Each point represents the mean of four separate experiments \pm SD. Half-maximal stimulation of GAP-43 phosphorylation occurred with $2 \times 10^{-10} \mathrm{M} 2.5 \mathrm{~S}$ NGF. $B$, Dose-response curve generated from the scintillation counts derived from GAP-43 spots cut out of 2-D gels, following separation of $1 G C$ proteins that had been incubated in vitro with NGF and ${ }^{32} \mathrm{P}$ ATP. Each point represents the mean of four separate experiments \pm SD. Half-maximal phosphorylation of GAP-43 occurred with $1 \times 10^{-10} \mathrm{M}$ 2.5S NGF. al., 1986; Rowland et al., 1987; Rowland-Gagne and Greene, 1990). Therefore, if the onset of GAP-43 phosphorylation in vivo is regulated by NGF, it should occur subsequent to binding of NGF to its high-affinity receptor. Before describing the experiments in which we investigated stimulation of GAP-43 phosphorylation by NGF, it is important to reemphasize that consistently quantifiable results using the IGCs were only obtained when air that contained $5 \% \mathrm{CO}_{2}$ was bubbled through the suspension of IGCs once every minute for $10 \mathrm{sec}$. We presume that, in the absence of bicarbonate in the Krebs's solution, the $\mathrm{CO}_{2}$ serves to maintain intracellular $\mathrm{pH}$ within a required range (reviewed by Frelin et al., 1988). Intact septal/hippocampal IGCs were prepared and preincubated for $30 \mathrm{~min}$ with ${ }^{32} \mathrm{P}$ orthophosphate, in Krebs's buffer as before. Maximal, twofold stimulation of GAP-43 phosphorylation could be detected after incubating the IGCs for 1 min with $4 \times 10^{10} \mathrm{M} 2.5 \mathrm{~S} \mathrm{NGF}$ (Fig. 3A,B), thus demonstrating that GAP-43 phosphorylation in intact IGCs can be regulated by NGF. The degree of stimulation by NGF observed is at least partly due to the fact that even IGCs prepared from septal/hippocampal areas contain low numbers of NGF receptors. For example, in an experiment where double-labeling immunohistochemistry was used to quantitate the number of IGCs reactive with both GAP-43 and the antibody $\Lambda 192$ against the NGF receptor (a gift of Dr. E. M. Johnson, Washington University School of Medicine), only $22 \% \pm 4 \%(N=100$ in each of 10 separate experiments $)$ of all the IGCs were immunoreactive for both GAP-43 and A192. The low concentration of NGF that evoked the response suggested that a high-affinity NGF receptor might be involved. We therefore generated a dose-response curve to quantitate the kinetics of stimulation of phosphorylation, which showed that the concentration of NGF required to cause half-maximal stimulation of phosphorylation was $2 \times 10^{-10} \mathrm{M}$.

To establish more accurately the concentration of NGF that would cause maximal incorporation of phosphate into GAP43, the experiments were repeated with an in vitro preparation in which a high-specific-activity ATP could be used to phosphorylate the IGC proteins. IGCs were prepared from the septal/ hippocampal areas of PI rat brains as described, gently lysed in hypotonic buffer, and then incubated with concentrations of 2.5S NGF ranging from $10^{-12} \mathrm{M}$ to $10^{-9} \mathrm{M}$ for $25 \mathrm{sec}$ in the presence of $200 \mu \mathrm{M} \gamma-{ }^{32} \mathrm{P}$-ATP (specific activity, $5 \mathrm{Ci} / \mathrm{mmol}$ ) in Krebs's buffer. Proteins were separated on 2-D IEF gels and stained with Coomassie blue, as before. In order to quantitate NGF-stimulated incorporation of phosphate into GAP-43 accurately, scanning absorbance densitometry of the spot that corresponded to GAP-43 was performed on the wet, Coomassie blue-stained 2-D gels. The scintillation counts derived from the GAP-43 spots that were then cut out of the dried gels were subsequently adjusted to reflect the actual amount of GAP-43 protein present. To validate this approach and to allow comparisons between samples to be made, each second-dimension SDS gel contained the acid, GAP-43-containing, end from each of four first-dimension gels. Furthermore, duplicate samples were always run on different second-dimension gels to control for any variation in the intensity of Coomassie blue staining. In this way, we were able to account for the subtle differences in loading onto the first-dimension gels that may have affected the reproducibility of the results. These considerations were especially important in the experiments where phosphorylation was measured by incubating the intact IGCs with radiolabeled phosphate. We used the scintillation counts to generate a dose- 


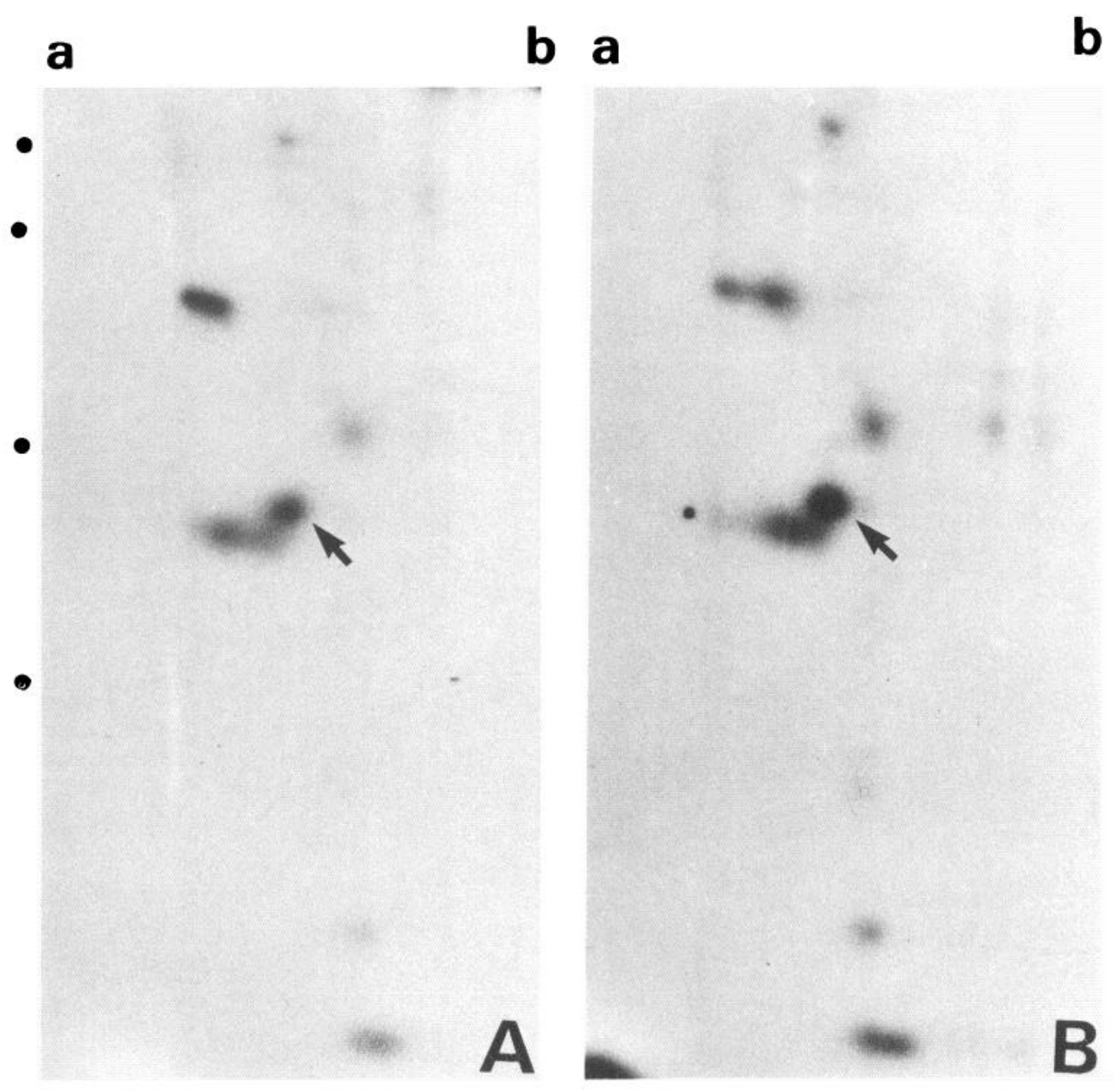

Figure 3. NGF-stimulated phosphorylation of GAP-43 in intact IGCs. $A$, Representative autoradiograph from which the dose-response curve was calculated. A $30 \mu \mathrm{g}$ aliquot of IGC proteins was preincubated with ${ }^{32} \mathrm{P}$-orthophosphate, and then the proteins separated by 2-D IEF electrophoresis, as described. The position of GAP-43 is indicated by arrows. $B$, Autoradiograph of $30 \mu \mathrm{g}$ aliquot of IGC proteins that was preincubated with ${ }^{32} \mathrm{P}$-orthophosphate and then with $4 \times 10^{-10} \mathrm{M}$ NGF for $5 \mathrm{~min}$, as described in Materials and Methods. Note the increased phosphorylation of GAP-43 (arrow) as well as other IGC proteins. The acidic end (a) of the IEF dimension is $\mathrm{pI} 4.1$; the basic $(b)$ is pI 8.5 , to the right.

response curve, which enabled us to determine that the minimum concentration of $2.5 \mathrm{~S}$ NGF that stimulated phosphate incorporation into GAP-43 was $2 \times 10^{-11} \mathrm{M}$, whereas maximum stimulation of phosphorylation measured occurred at $2 \times 10^{-9}$ M (Fig. 2). This result is consistent with the interpretation that stimulation of GAP-43 phosphorylation in the septal and hippocampal IGCs occurred subsequent to the binding of NGF to its biologically active high-affinity receptor (Green and Greene, 1986).

\section{$N G F$-stimulated phosphorylation of GAP-43 occurs on serine ${ }^{41}$}

One drawback to the use of incorporation of radiolabeled phosphate to measure stimulation of protein phosphorylation in intact systems is that it is not possible to determine whether the actual number of phosphorylated molecules has increased or whether the increased phosphate incorporation is merely a result of stimulation of the turnover of phosphate on the same number of phosphorylated molecules. This distinction is of particular importance here since the in vivo results had clearly shown an increased number of phosphorylated GAP-43 molecules in growth cones approaching their targets (Meiri et al., 1991). In those experiments, we used a monoclonal antibody, $2 \mathrm{G} 12$, that specifically recognizes phosphoserine ${ }^{41}$, the amino acid phosphorylated by kinase $\mathrm{C}$, to detect the increased numbers of GAP43 molecules in the growth cones. Thus, if NGF is responsible for the increased phosphorylation of GAP-43 that we observed in vivo, increased phosphorylation of GAP-43 in response to
NGF should be detectable with the 2 G12 antibody in the IGCs, also. We therefore determined whether serine ${ }^{41}$ on GAP-43 is phosphorylated following NGF treatment as follows: IGCs were phosphorylated with $4 \times 10^{-9} \mathrm{M}$ NGF. GAP-43 was purified from them by base extraction and reverse-phase HPLC (Fig. $4 A, B)$ and then subjected to tryptic digestion, as we have described before (Meiri et al., 1991). Stimulation of GAP-43 phosphorylation by NGF generated a single phosphopeptide that was sequenced as IQAS( $\left(\mathrm{PO}_{4}\right) \mathrm{FR}$ (indicating that radiolabeled phosphate was evolved on the fourth cycle). This sequence, which arises from GAP-43 residues $38-43$ and includes serine $\mathrm{e}^{41}$, the kinase $\mathrm{C}$ phosphorylation site, is the one that reacts with the monoclonal antibody $2 \mathrm{G} 12 / \mathrm{C} 7$, as we have shown previously (Meiri et al., 1991). Although this result gives us no direct information as to the kinase responsible for generating phosphoserine ${ }^{41}$, it is consistent with the results obtained in vivo and furthermore means that we were able to use the antibody to quantitate the NGF-induced changes in numbers of phosphorylated GAP-43 molecules in intact IGCs that could not have been determined solely by examining incorporation of radiolabeled phosphate.

\section{$N G F$ increases and maintains the steady state levels of GAP-43 phosphorylation in IGCs}

In experiments where the antibody $2 \mathrm{G} 12$ was used to measure actual levels of phosphorylated GAP-43 in intact IGCs, septal and hippocampal IGCs were prepared as before but were not 

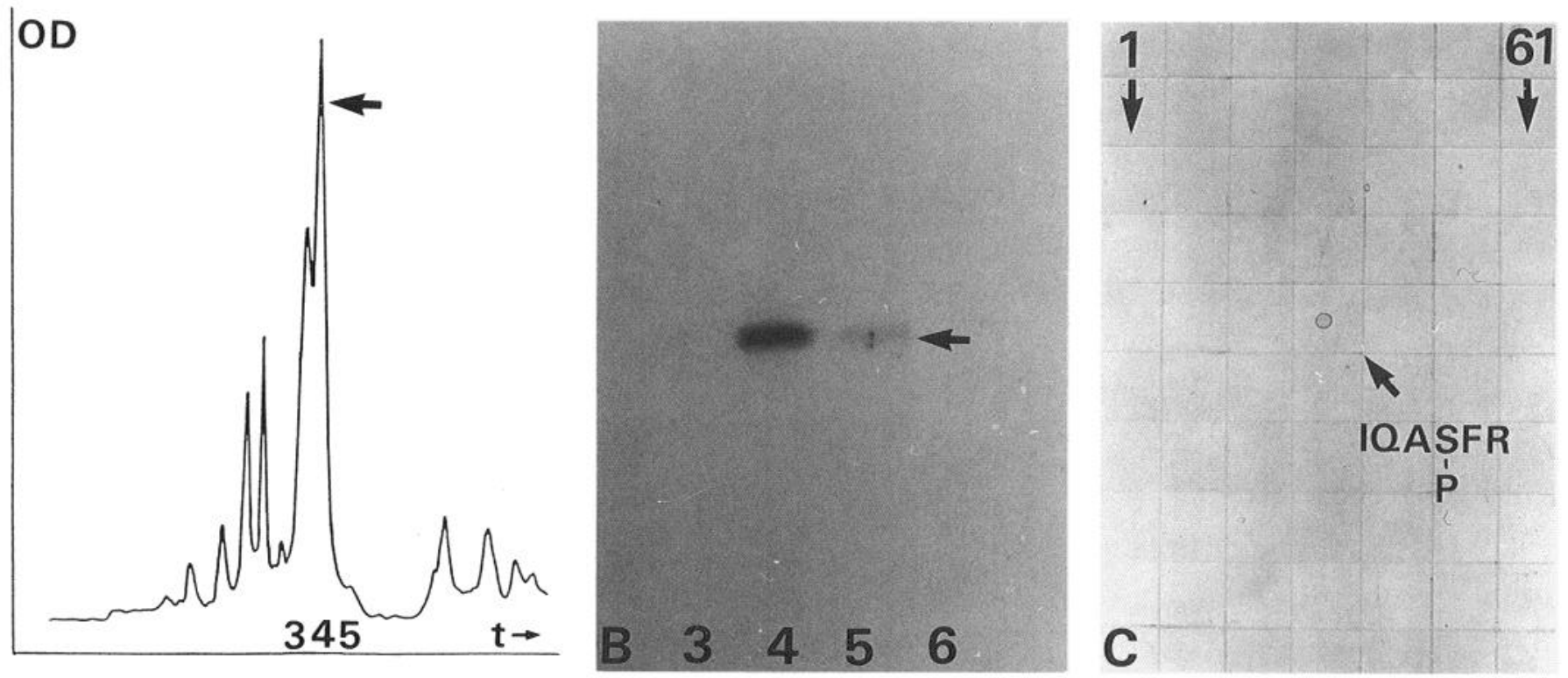

Figure 4. Identification of serine ${ }^{41}$ as the residue phosphorylated in response to NGF. A, Optical density (monitored at $214 \mathrm{~nm}$ ) of IGC proteins that had been incubated with $4 \times 10^{-9} \mathrm{M}$ NGF. Peaks due to GAP-43 are shown with an arrow. Numbers refer to HPLC fractions. $B$, Autoradiograph of 1-D 10\% SDS gel of aliquots of fractions from the HPLC. (Numbers are in sequence with the fractions numbered in $A$.) The band due to radiolabeled GAP-43 is shown with an arrow. $C$, Aliquots of the tryptic peptides obtained by proteolysis of the radiolabeled GAP-43 identified in $B$ were manually dotted onto polyvinyldifluoride membrane, reacted with the antibody $2 \mathrm{G} 12$, and immunoreactivity was visualized with diaminobenzidine. The single immunoreactive spot (arrow) corresponded to the single phosphopeptide that had the sequence IQASFR.

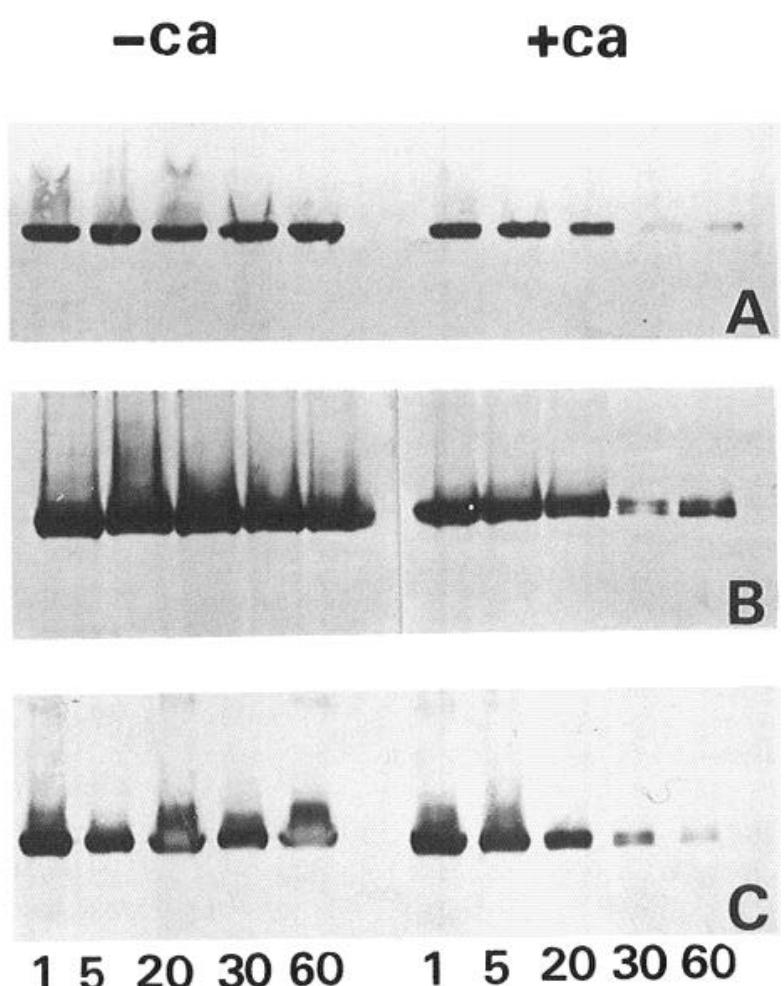

Figure 5. Detection of NGF-stimulated increases in levels of phosphorylated GAP-43 in intact IGCs. Western blots of $10 \%$ SDS gels of IGC proteins that had been incubated at $37^{\circ} \mathrm{C}$, aerated, for the times (in minutes) indicated at the bottom. Anti-GAP-43 phosphoserine ${ }^{41}$ immunoreactivity was detected with $2 \mathrm{G} 12$ antibody. $A$, Controls: left side in the presence of Krebs's solution; right side in the presence of Krebs's solution containing $1.2 \mathrm{~mm} \mathrm{CaCl}_{2}$ and $1 \mu \mathrm{M} \mathrm{A} 23187 . B$, In the presence of $10 \mathrm{~nm}$ PDBU: left side and right side as above. $C$, In the preincubated with radiolabeled orthophosphate. Thus, IGC proteins were phosphorylated by the unlabeled ATP endogenous to the IGCs, and increased phosphorylation of GAP-43 was measured as increased immunoreactivity with the monoclonal antibody $2 \mathrm{G} 12$. In order to detect stimulation of GAP-43 phosphorylation by NGF, proteins from IGCs that had been incubated with NGF as before were separated by 1-D SDS-PAGE and Western blotted. Quantitation of 2G12 immunoreactivity on the Western blots by reflectance densitometry (Meiri and Gordon-Weeks, 1990) showed a twofold increase in 2G12 immunoreactivity, reflecting increased phosphorylation of serine ${ }^{41}$ (compare Fig. 5A,C; for quantitation, see also Fig. $6 A$ ). This result demonstrates that NGF actually increased the net number of phosphorylated GAP-43 molecules in the IGCs rather than merely inducing turnover of radiolabeled phosphate on the same number of phosphorylated molecules. Moreover, the approximately twofold increase in phosphorylation detected by antibody immunoreactivity is similar to the increase in radiolabeled phosphate incorporated into GAP-43 on NGF treatment, thus confirming that in these experiments the radiolabeling technique did accurately reflect the phosphorylation state of GAP-43 in intact IGCs. In other experiments where the IGCs were incubated in the presence of NGF for up to $2 \mathrm{hr}$, the increase in steady state levels of phosphorylated GAP-43 was maintained throughout that time (Fig. 5C). Furthermore, when similar experiments were also repeated using phorbol ester rather than

presence of $4 \times 10^{-10} \mathrm{M} 2.5 \mathrm{~S}$ NGF. Note the increased phosphorylation of GAP-43 in the NGF-treated IGCs compared with controls, and also the calcium-dependent dephosphorylation of GAP-43 that occurred in each case. Seven micrograms of total IGC protein were loaded into each lane. The experiment was repeated five times with similar results. 

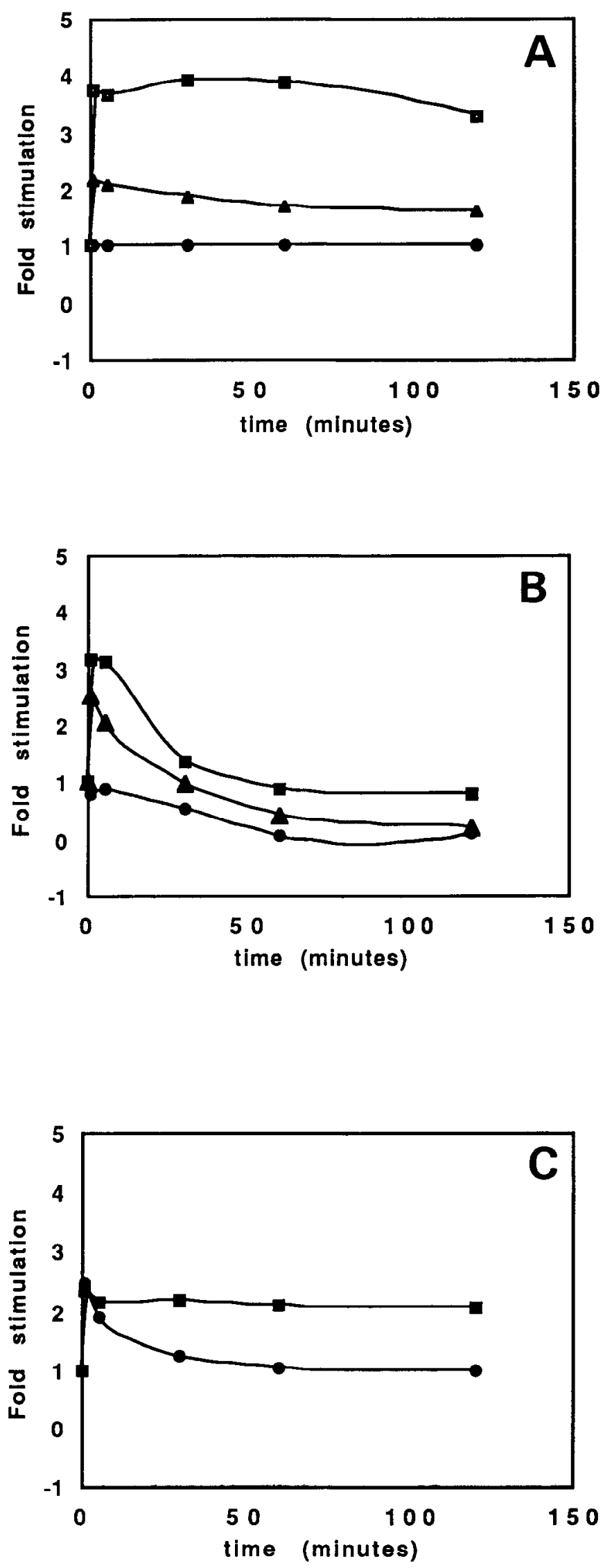

Figure 6. Time course of GAP-43 phosphorylation and dephosphorylation in intact IGCs. Western blots similar to those in Figure 5 were scanned using reflectance densitometry, and the area under the curve
NGF, the increased phosphorylation of GAP-43 detected also resembled that seen in the radiolabeling experiments (compare Fig. $5 A, B$; for quantitation, see also Fig. $6 A$ ).

\section{Calcium-stimulated dephosphorylation and proteolysis of GAP-43 in intact IGCs}

In the experiments in which intact IGCs were incubated for up to $2 \mathrm{hr}$ with either $4 \times 10^{\circ} \mathrm{M}$ NGF or $10 \mathrm{~nm}$ phorbol ester, a loss of immunoreactivity with $2 \mathrm{G} 12$ was seen whenever $1.2 \mathrm{~mm}$ calcium and $1 \mu \mathrm{M} \mathrm{A23187}$ were also included in the incubation solution (Fig. $5 B, C$ ). Under these circumstances, the loss of immunoreactivity that occurred even if NGF or phorbol ester was present throughout the incubation period became evident after about $5 \mathrm{~min}$ and had a half-time of about $20 \mathrm{~min}$. Loss of immunoreactivity was also detected in the absence of added calcium and A23187 if stimulators of phosphorylation were removed from the incubation solution after the initial $1 \mathrm{~min}$ incubation (Fig. 6C). To determine whether this loss of immunoreactivity was caused by dephosphorylation or proteolysis of GAP-43, 1-D gels and Western blots were generated from parallel samples taken at the end of the incubation period $(60$ min), a time when loss of immunoreactivity would be expected to be maximal. For direct comparison, one of the samples was reacted with the antibody $5 \mathrm{E} 7$, which recognizes both phosphorylated and unphosphorylated GAP-43, while the other was reacted with $2 \mathrm{G} 12$. There was loss of immunoreactivity from both samples, but it was much more significant in the sample reacted with $2 \mathrm{G} 12$, reflecting dephosphorylation (Fig. 7). In contrast, the loss of immunoreactivity detected by $5 \mathrm{E} 7$, presumably due to proteolysis, was variable but never exceeded $20 \%$ of the total loss of immunoreactivity. Thus, both dephosphorylation and proteolysis of GAP-43 in intact IGCs occur; both may represent important regulatory mechanisms and may be differentially stimulated. Loss of $2 \mathrm{G} 12$ immunoreactivity could be prevented by including $1 \mathrm{~mm}$ EGTA in the Krebs's solution but was not inhibited by concomitant incubation of the IGCs with $1 \mu \mathrm{M}$ okadaic acid, a phosphatase -1 or $-2 \mathrm{~A}$ inhibitor that is active in intact systems (see Haystead et al., 1989). While these experiments make no attempt to identify the relevant phosphatase, the results are consistent with the calcineurin-dependent dephosphorylation of GAP-43 previously observed to occur in vitro (Liu and Storm, 1989). We did not investigate the calcium-stimulated proteolysis.

\footnotetext{
was used to determine the degree of stimulation of phosphorylation (or dephosphorylation) of GAP-43. In each case, the values derived from either NGF- or phorbol ester-treated GAP-43 were compared to untreated controls at the same time point. $A$, Although stimulation of phosphorylation is maintained for up to $2 \mathrm{hr}$ in the presence of either NGF $(\boldsymbol{\Delta})$ or phorbol ester $(\mathbf{0})$ compared with controls $(\boldsymbol{\theta})$, NGF stimulated phosphorylation about twofold, whereas phorbol ester stimulated it about fourfold. $B$, Similar plots derived from reflectance densitometry of immunoreactive GAP-43 bands from IGCs that had been incubated in the presence of NGF $(\Delta)$ or $10 \mathrm{nM}$ phorbol ester $(0)$ together with

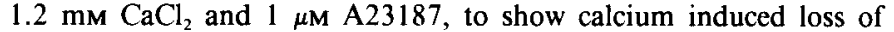
immunoreactivity, probably dephosphorylation. $C$, Similar plot comparing GAP-43 from NGF-treated IGCs that were either incubated in Krebs's solution with NGF ( $\square$ ), or that had the NGF removed after an initial $5 \mathrm{~min}$ incubation (O) to demonstrate that dephosphorylation of GAP-43 can occur even without extracellular calcium provided that any stimulators of phosphorylation are also not present throughout the incubation period. In each case, $3 \mu \mathrm{g}$ of protein had been loaded onto each lane to maintain the signal within the linear range of the instrument. The experiment was repeated five times with similar results.
} 


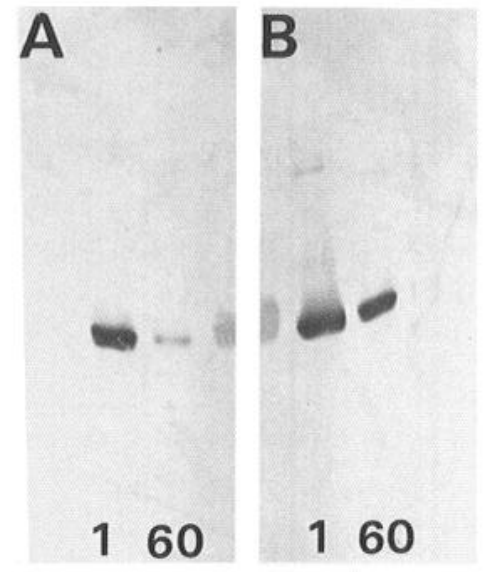

Figure 7. Calcium-dependent loss of $2 \mathrm{G} 12$ immunoreactivity. Western blots of 1-D $10 \%$ SDS gels of IGC proteins reacted with 2 G12 $(A)$ and reacted with the antibody $5 \mathrm{E} 7$ that reacts with both phosphorylated and unphosphorylated forms $(B)$. All of the samples were derived from the same fraction of IGCs that was incubated with NGF together with $\mathrm{CaCl}_{2}$ and $\mathrm{A} 23187$ for either 1 min (left side of both) or 60 min (right side of both). Note that after $60 \mathrm{~min} 2 \mathrm{G} 12$ immunoreactivity, that is, phosphorylated GAP-43, is nearly absent (right side of $A$ ), whereas the equivalent aliquot reacted with 5E7 shows a much smaller decrease in the total amount of GAP-43 present (right side of $B$ ). Seven micrograms were loaded into each lane. In the center lane, the prestained molecular weight standard fumarase $(47 \mathrm{kDa})$ is bisected since both panels were originally derived from the same Western blot.

\section{Discussion}

We have combined two novel approaches in order to study the regulation of GAP-43 phosphorylation in growth cones. First, we have demonstrated ATP synthesis in a subcellular fraction of intact IGCs. Direct activation of protein kinase $\mathrm{C}$ with phorbol ester stimulated the phosphorylation of known kinase $\mathrm{C}$ substrates including GAP-43 in these IGCs, thus demonstrating the use of the preparation for studying phosphorylation reactions in the intact growth cone, since it circumvents the problem of biochemically distinguishing events occurring at the growth cone from those ongoing elsewhere in the neuron. Second, as an adjunct to this approach we have used our monoclonal antibody 2 G12, which specifically detects the GAP-43 residue phosphoserine ${ }^{41}$, to show that NGF-dependent phosphorylation of GAP-43 in these intact IGCs occurs on serine ${ }^{41}$, the kinase $\mathrm{C}$ phosphorylation site. Furthermore, we demonstrated that incubation of intact IGCs with NGF causes a net increase in steady state levels of phosphorylated GAP-43 and that GAP-43 is also subject to calcium-stimulated dephosphorylation that is inhibited by EGTA but not okadaic acid.

Our results support the interpretation that NGF-stimulated phosphorylation of GAP-43 occurs subsequent to binding of NGF to a high-affinity receptor for the following reasons. First, significant stimulation of GAP-43 phosphorylation by NGF was detected only in IGCs prepared from septal and hippocampal areas of P1 rat forebrains and not in those from whole forebrain, in agreement with immunohistochemical and in situ hybridization studies that show high levels of NGF receptor in septal and hippocampal areas at this stage during neuronal development (Buck et al., 1988; Ernfors et al., 1988; Maisonpierre et al., $1990 \mathrm{a}, \mathrm{b})$. In contrast, no differences in the degree of phorbol ester-stimulated GAP-43 phosphorylation was seen between IGCs prepared from whole forebrains and those derived from septal and hippocampal areas. Second, our experiments with intact IGCs show that 2.5S NGF stimulates phosphorylation of GAP-43 within 1 min with a $K_{d}$ of $2 \times 10^{-10} \mathrm{M}$ that is significantly higher than the $K_{d}$ for binding to its low-affinity receptor, which is $10^{-9} \mathrm{M}$. Finally, although NGF can bind with both high and low affinity to the same gene product (Green and Greene, 1986), its biological effects are mediated solely following highaffinity interactions (Hosang and Shooter, 1985, 1987; Green et al., 1986). The high-affinity receptor seems to be formed from the coupling of the NGF-binding protein to an intracellular component capable of transducing the extracellular binding event; such transduction is not evident following binding of NGF to the low-affinity receptor (see, e.g., Hempstead et al., 1990, 1991; Meakin and Shooter, 1991). Our data, which shows the intracellular activation of a kinase following treatment of intact IGCs with concentrations of NGF sufficient to activate a high-affinity receptor, therefore suggest that GAP-43 phosphorylation may be part of the repertoire of biologically relevant responses of growth cones to NGF. It is possible that other target-derived growth factors may have similar effects on GAP-43 phosphorylation; a number of molecules with sequence homology to NGF have been isolated, for example BDNF and NT3, and there may be cross reactivity between these molecules and their receptors (Leibrock et al., 1989; Hohn et al., 1990; Maisonpierre et al., 1990a,b).

Knowledge of how the NGF-binding event is transduced intracellularly is incomplete. Unlike other growth factor receptors, the NGF-binding protein does not have intrinsic kinase activity (Grob et al., 1985; Taniuchi et al., 1986). Nevertheless, it is able to activate a number of second messengers and protein kinases (McTigue et al., 1985; Hama et al., 1986; Rowland et al., 1987; Hall et al., 1988; Maher, 1988, Hempstead et al., 1991). While our results show NGF-dependent phosphorylation of GAP-43 to be occurring on serine ${ }^{41}$, the only site phosphorylated by kinase $\mathrm{C}$ in vitro, they nevertheless do not rule out the possibility that in vivo this residue may also be a substrate for other serine kinases.

The monoclonal antibody 2G12 also allowed us to detect calcium-stimulated dephosphorylation of GAP-43. This dephosphorylation was detected under two circumstances. In the presence of extracellular calcium and A23187, dephosphorylation occurred and could only be prevented by EGTA. In the absence of added calcium, dephosphorylation of GAP-43 would occur following NGF-stimulated phosphorylation whenever NGF was removed from the incubation buffer but could be prevented by keeping NGF present throughout. Taken together with our previous results showing the precise temporal regulation of GAP-43 phosphorylation in vivo (Meiri et al., 1991), these results imply that maintenance of the phosphorylated state subsequent to its induction requires continued extracellular input, in this case by NGF. We have not identified the calciumdependent phosphatase responsible for dephosphorylating GAP43 , but the results that show that it is not inhibitable by $1 \mu \mathrm{M}$ okadaic acid suggest that it is not phosphatase 2A (Haystead et al., 1989). Consistent with these results, calcium- and calmodulin-dependent dephosphorylation of GAP-43 in vitro by calcineurin has been reported (Liu and Storm, 1989).

Is there normally a balance between phosphorylation and dephosphorylation of GAP-43 in growth cones, and if so how might it be regulated? These results do not allow us to identify the source of calcium but suggest that it is locally regulated so that we might expect to see changes in levels of phosphorylated 
GAP-43 that reflect some underlying changes in growth cone behavior. In support of this speculation, we have recent evidence that in regenerating growth cones in vitro, different growth cones arising from the same cell body, and also different areas of the same growth cone, can be differentially phosphorylated with respect to GAP-43 (Dent and Meiri, 1991).

What might be the biological consequences of the regulated phosphorylation of GAP-43 by NGF in growth cones? Even though our evidence shows that NGF can maintain levels of phosphorylated GAP-43 in these IGCs, we are reluctant to propose a specific role for GAP-43 in NGF receptor function. Rather, taking this information together with previous studies that have correlated GAP-43 phosphorylation with a number of physiologically relevant signals, we believe that our data further support the hypothesis that kinase activation and phosphorylation of GAP-43 on serine ${ }^{41}$ provide a means whereby the growth cone can respond similarly to stimuli of diverse origins. In molecular terms, it will now be necessary to determine whether NGF-maintained phosphorylation of GAP-43 affects its specific interactions with other growth cone membrane skeleton proteins.

\section{References}

Bradford MM (1976) A rapid and sensitive method for the quantification of microgram quantities of protein utilizing the principle of protein-dye binding. Anal Biochem 72:248-254.

Bray D, Hollenbeck PJ (1988) Growth cone motility and guidance. Annu Rev Cell Biol 4:43-61.

Buck CR, Martincz HJ, Moscs CV, Black IB (1988) Differential expression of the nerve growth factor receptor gene in multiple brain areas. Dev Brain Res 44:259-268.

Caudy M, Bentley D (1986) Pioneer growth cone steering along a series of neuronal and non-neuronal cues of different affinities. J Neurosci 6:1781-1785.

Chitnis AB, Kuwada JY (1990) Axonogenesis in the brain of zebrafish embryos. J Neurosci 10:1892-1905.

Cremins J, Wagner JA, Halegoua S (1986) Nerve growth factor action is mediated by cyclic AMP- and $\mathrm{Ca}^{+2} /$ phospholipid-dependent protein kinases. J Cell Biol 103:887-893.

Dekker LV, DeGraan PN, Oestreicher AB, Versteeg DH, Gispen WH (1989) Inhibition of noradrenaline release by antibodies to B-50. Nature 342:74-76.

Dekker LV, DeGraan PN, Oestreicher AB, DeWit M, Hens JJ, Gispen WH (1990) Depolarization-induced phosphorylation of the protein kinase C substrate B-50 (GAP-43) in rat cortical synaptosomes. J Neurochem 54:1645-1652.

Dent EW, Meiri KF (1991) Local regulation of GAP-43 phosphorylation in individual growth cones. Soc Neurosci Abstr, in press.

Ernfors P, Ebendal T, Olson L, Mouton P, Stromberg I, Persson H (1988) Developmental and regional expression of $\beta$ nerve-growth factor receptor mRNA in the chick and the rat. Neuron 1:983-996.

Frelin C, Vigne P, Ladoux A, Lazdunski M (1988) The regulation of intracellular $\mathrm{pH}$ in cells from vertebrates. Eur J Biochem 174:3-14.

Gogstad GO, Krutnes MG (1982) Measurement of protein in cell suspensions using the Coomassie brilliant blue dye-binding assay. Anal Biochem 126:355-359.

Gordon-Weeks PR (1987) Isolation of synaptosomes, growth cones and their subcellular components. In: Neurochemistry: a practical approach (Turner AJ, Bachelard HS, eds), pp 1-26. Oxford: IRL.

Gordon-Weeks PR, Lockerbie RO (1984) Isolation and partial characterization of neuronal growth cones from neonatal rat forebrain. Neuroscience 13:119-136.

Green SM, Greene LA (1986) A single $M_{r}$ approximately $103,000^{125} \mathrm{I}-$ beta-nerve growth factor-affinity-labeled species represents both the low and high affinity forms of the nerve growth factor receptor. J Biol Chem 261:15316-15326.

Green SM, Rydel RM, Connolly JL, Greene LA (1986) PC12 mutants that possess low- but not high-affinity nerve growth factor receptors neither respond to nor internalize nerve growth factor. J Cell Biol 102:830-843.
Grob PM, Ross AH, Koprowski M, Bothwell MA (1985) Characterization of the human melanoma nerve growth factor receptor. J Biol Chem 260:8044-8049.

Gundersen RW (1987) Response of sensory neurites and growth cones to patterned substrata of laminin and fibronectin in vitro. Dev Biol 121:423-431.

Hall FL, Fernyhough P, Ishii DN, Vulliet PR (1988) Suppression of nerve growth factor-directed neurite outgrowth in PC12 cells by sphingosine, an inhibitor of protein kinase C. J Biol Chem 263:44604466 .

Hama T, Huang KP, GuroffG (1986) Protein kinase C as a component of a nerve growth factor-sensitive phosphorylation system in $\mathrm{PCl} 2$ cells. Proc Natl Acad Sci USA 83:2353-2357.

Haystead TAJ, Sim ATR, Caling D, Honnor RC, Tsukitani Y, Cohen P, Hardie DG (1989) The effects of the tumor promoter okadaic acid on intracellular protein phosphorylation and metabolism. Nature $337: 78-81$

Hempstead BI, Patil N, Thiel B, Chao M (1990) Deletion of cytoplasmic sequences of the nerve growth factor receptor leads to loss of high affinity ligand binding. J Biol Chem 265:9595-9598.

Hempstead BL, Martin-Zanca D, Kaplan DR, Parada LF, Chao MV (1991) High affinity NGF binding requires co-expression of the trk proto-oncogene and the low affinity NGF receptor. Nature 350:678683.

Hohn A, Leibrock J, Bailey K, Barde Y-A (1990) Identification and characterization of a novel member of the nerve growth factor/brain derived neurotrophic factor family. Nature 344:339-341.

Hosang M, Shooter EM (1985) Molecular characteristics of nerve growth factor receptors on PC12 cells. J Biol Chem 260:655-662.

Hosang M, Shooter EM (1987) The internalization of nerve growth factor by high-affinity receptors on pheochromocytoma $\mathrm{PCl} 2$ cells. EMBO J 6:1197-1202

Kuwada JY, Bernhardt RR, Chitnis AB (1990) Pathfinding by identified growth cones in the spinal cord of zebrafish embryos. J Neurosci 10:1299-1308.

Laemmli UK (1970) Cleavage of structural proteins during the preassembly of the head of bacteriophage T4. Nature 227:680-685.

Lander AD (1987) Molecules that make axons grow. Mol Neurobiol $1: 213-245$

Leibrock J, Lottspeich F, Hohn A, Hofer M, Hengerer B, Masiakowski P, Thoenen H, Barde Y-A (1989) Cloning and expression of brainderived neurotrophic factor. Nature 341:149-152.

Liu Y, Storm DR (1989) Dephosphorylation of neuromodulin by calcineurin. J Biol Chem 264:12800-12804.

Lockerbie RO, Gordon-Weeks PR, Pearce BR (1985) Growth cones isolated from developing rat forebrain: uptake and release of GABA and noradrenaline. Dev Brain Res 2:265-275.

Maher PA (1988) Nerve growth factor induces protein-tyrosine phosphorylation. Proc Natl Acad Sci USA 85:6788-6791.

Maisonpierre PC, Belluscio L, Friedman B, Alderson R, Wiegand S, Furth M, Lindsay RM, Yancopoulos G (1990a) NT-3, BDNF, and NGF in the developing rat nervous system: parallel as well as reciprocal patterns of expression. Neuron 5:501-509.

Maisonpierre PC, Belluscio L, Squinto S, Ip NY, Furth ME, Lindsay RM, Yancopoulos G (1990b) Neurotrophin-3: a neurotrophic factor related to NGF and BDNF. Science 247:1446-1451.

Mangeat PH (1988) Interaction of biological membranes with the cytoskeletal framework of living cells. Biol Cell 64:261-281.

Matsunaga M, Hatta K, Nagafuchi A, Takeichi M (1988) Guidance of optic nerve fibres by $\mathrm{N}$-cadherin adhesion molecules. Nature 334: 62-64.

McTigue M, Cremins J, Halegoua S (1985) Nerve growth factor and other agents mediate phosphorylation and activation of tyrosinc hydroxylase. A convergence of multiple kinase activities. J Biol Chem 260:9047-9056.

Meakin SO, Shooter EM (1991) Molecular investigations on the high affinity nerve growth factor receptor. Neuron 16:153-163.

Meiri KF, Gordon-Weeks PR (1990) GAP-43 in growth cones is associated with areas of membrane that are tightly bound to substrate and is a component of membrane skeleton subcellular fraction. $\mathrm{J}$ Neurosci 10:256-266.

Meiri KF, Pfenninger KH, Willard M (1986) Growth associated protein, GAP-43, a polypeptide that is induced when neurons extend axons, is a component of growth cones and corresponds to pp 46 a major polypeptide of a subcellular fraction that is enriched in growth cones. Proc Natl Acad Sci USA 83:3537-3541. 
Meiri KF, Willard M, Johnson MI (1988) Distribution and phosphorylation of the growth associated protein GAP-43 in regenerating sympathetic neurons in culture. J Neurosci 8:3537-3542.

Meiri KF, Bickerstaff LE, Schwob JE (1991) Monoclonal antibodies show that kinase $\mathrm{C}$ phosphorylation of GAP-43 during axonogenesis is both spatially and temporally restricted in vivo. J Cell Biol 112: 991-1007.

Pfenninger KH (1987) Plasmalemmal properties of the sprouting neuron. Curr Top Dev Biol 21:185-206.

Read SM, Northcote DH (1981) Minimization of variation in the response to different proteins of the Coomassie blue $\mathrm{G}$ dye-binding assay for protein. Anal Biochem 116:53-64.

Rowland EA, Muller TH, Goldstein M, Greene LA (1987) Cell-free detection and characterization of a novel nerve growth factor-activated protein kinase in PC12 cells. J Biol Chem 262:7504-7513.

Rowland-Gagne E, Greene LA (1990) Multiple pathways of N-kinase activation in PC12 cells. J Neurochem 54:423-433.

Skenc JHP, Willard M (1981) Axonally transported proteins associated with growth in rabbit central and peripheral nervous system. $J$ Cell Biol 89:96-103.
Taniuchi M, Iohnson EM, Roach PI, Lawrence PC (1986) Phosphorylation of nerve growth factor receptor proteins in sympathetic neurons and PC12 cells. J Biol Chem 261:13342-13346.

Tomaselli KJ, Reichardt LF, Bixby JL (1986) Distinct molecular interactions mediate neuronal process outgrowth on non-neuronal cell surfaces and extracellular matrices. J Cell Biol 103:2659-2672.

Tosney KW, Landmesser LT (1985a) Growth cone morphology and trajectory in the lumbosacral region of the chick embryo. $J$ Neurosci 5:2345-2358.

Tosney KW, Landmesser LI (1985b) Specificity of early motoneuron growth cone outgrowth in the chick embryo. J Neurosci 5:2336-2344.

Van Hoof COM, DeGraan PN, Oestreicher AB, Gispen WH (1989) Muscarinic receptor activation stimulates B50/GAP-43 phosphorylation in isolated nerve growth cones. J Neurosci 9:3753-3760.

Yip RK, Kelly PY (1989) In situ protein phosphorylation in hippocampal tissue slices. J Neurosci 9:3618-3631. 